\title{
RANCANG BANGUN APLIKASI TRANSAKSI ELEKTRONIK RITEL PUPUK DENGAN METODE ELECTRONIC DATA INTERCHANGE (EDI)
}

\author{
Nelly Oktavia Adiwijaya, Nurul Istiana M, Slamin \\ Program Studi Sistem Informasi \\ Universitas Jember \\ e-mail: nelly.oa@unej.ac.id
}

\begin{abstract}
Abstrak-Pendistribusian pupuk dari distributor kepada agen-agen, distributor dituntut untuk cepat tanggap dalam menangani permintaan pupuk. Distributor juga dituntut untuk dapat mengelola jumlah pupuk di gudang, sehingga tidak terjadi penumpukan pupuk. Pembuatan rancang bangun aplikasi transaksi elektronik ritel pupuk dengan menggunakan metode electronic data interchange (EDI) diterapkan dalam penelitian ini. Sistem yang dibangun dapat membantu distributor untuk mengontrol keberadaan stok pupuk agar tidak over stock. Selain itu, penggunaan metode EDI dapat memberikan informasi secara cepat (realtime) tanpa harus mendatangi langsung lokasi gudang.
\end{abstract}

Kata Kunci : Aplikasi, Ritel, Electronic data interchange (EDI)

\begin{abstract}
Fertilizer distribution from distributor to agents, are required to be responsive in addressing the demand for fertilizers. Distributors are also required to be able to manage inventory in the warehouse, to avoid overstocking of fertilizer. Design and implementation of a fertilizer retail electronic commerce applications using electronic data interchange (EDI) method is applied in this study. The system is built to help distributors to control the existence of the stock of fertilizer so no excess stock. In addition, the use of EDI can provide information quickly (real-time) without having to go directly to the warehouse locations.
\end{abstract}

Keywords : Application, Retail, Electronic data interchange (EDI)

\section{PENDAhULUAN}

Penggunaan teknologi informasi pada jaman sekarang dapat dijumpai di berbagai bidang seperti di bidang ekonomi, sosial, budaya dan politik. Di bidang ekonomi, teknologi informasi digunakan untuk mencatat berbagai pembukuan ke dalam sebuah sistem yang terkomputerisasi sehingga dapat memudahkan pengguna (user) dalam mengelola data-datanya. Usaha Dagang Trisa Jaya Makmur (UD. TJM) merupakan salah satu usaha dagang yang ada di kabupaten Jember yang bergerak di berbagai bidang usaha antara lain distributor pupuk NPK plus organik, busana, asesoris, dan lain-lain. Bidang usaha pendistribusian pupuk NPK plus organik yang dimiliki UD. TJM merupakan bidang usaha yang luas cakupannya dibandingkan dengan bidang usaha lainnya. Karena bidang usaha ini tidak hanya dipasarkan di sekitar UD. TJM berada, melainkan wilayah pemasarannya mencakup seluruh wilayah di kabupaten Jember. Dalam pendisribusian pupuk kepada agen-agen, distributor dituntut untuk cepat tanggap dalam menangani permintaan pupuk. Distributor juga dituntut untuk dapat mengelola jumlah pupuk di gudang, sehingga tidak terjadi penumpukan pupuk di gudang.

Pada penelitian yang pernah dilakukan sebelumnya oleh Gunawan (1999), "Dengan menggunakan sistem informasi yang terintegrasi ditambah dengan teknologi Electronic Data Interchange (EDI) dalam pertukaran dokumen dengan mitra dagang, sistem logistik perusahaan retail mampu ditingkatkan kinerjanya sehingga dapat mengurangi kesalahan dalam memasukkan data, mengurangi leadtime, mengurangi biaya dengan kombinasi atau eliminasi prosedur, menghilangkan pemakaian dokumen, menghilangkan pemakaian gudang, mengurangi inventori serta meningkatkan hubungan kerjasama antara retailer dengan mitra-mitra dagangnya". Pada penelitian ini akan dibuat rancang bangun aplikasi transaksi elektronik dengan menggunakan metode EDI. Dengan adanya aplikasi EDI, diharapkan dapat membantu pemilik untuk mengontrol keberadaan pupuk agar tidak over stock. 


\section{TINJAUAN PUSTAKA}

EDI merupakan kepanjangan dari Electronic Data Interchange yang didefinisikan sebagai komunikasi yang terjadi antar perusahaan dari satu aplikasi komputer ke komputer lainnya dengan pesan standar yang telah disepakati (Surjasa, 1998). Gambaran EDI secara umum dapat dilihat pada Gambar 1.

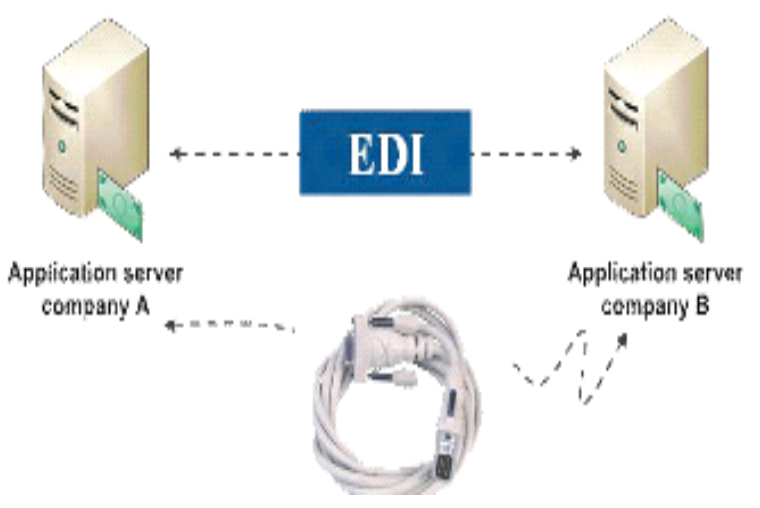

Gambar 1. Gambaran aplikasi EDI

Sumber: (Liegl, 2009)

Dokumen yang dipertukarkan dalam EDI dapat berupa dokumen pemesanan, tagihan, pembayaran, pengiriman dan lain - lain. Beberapa tipe dokumen yang dipertukarkan dalam EDI dapat dilihat pada Gambar 2.

Tujuan dari penggunaan teknologi EDI yaitu agar dapat membantu para pelaku bisnis mengkomunikasikan dokumen transaksinya dengan pihak lain lebih cepat, akurat dan efisien. Sehingga dapat meminimalisir kesalahan yang diakibatkan kesalahan dalam memasukkan data dan dapat mengurangi pemakaian kertas, biaya komunikasi dan biaya - biaya lain yang diakibatkan jika menggunakan pertukaran dokumen secara manual. Dengan demikian diharapkan dapat meningkatkan keuntungan kepada perusahaan. Apabila proses tersebut terpenuhi maka proses bisnis internal dalam perusahaan akan menjadi lebih baik, terstruktur dan terencana. Untuk melihat perbandingan antara proses pertukaran data yang dilakukan secara konvensional dengan proses pertukaran data dengan EDI, dapat dilihat pada Gambar 3.

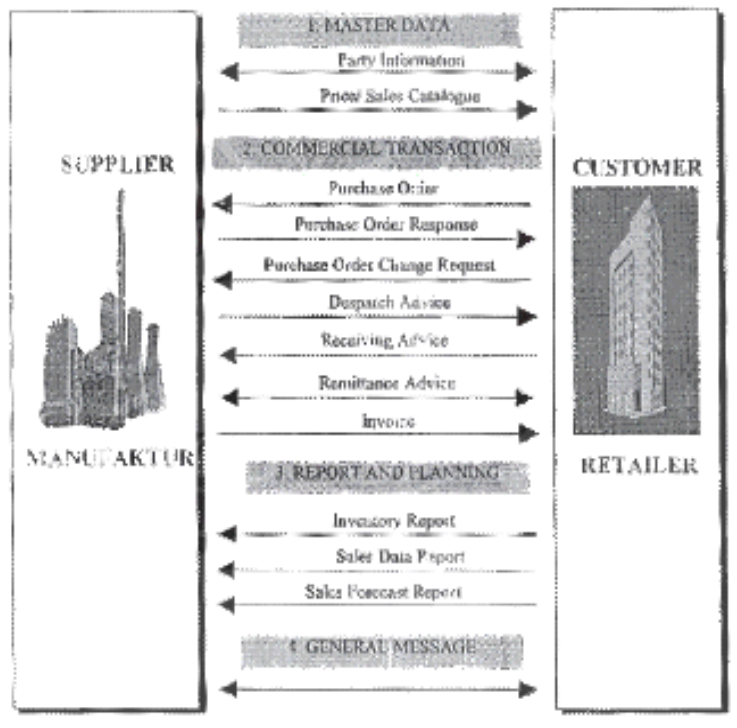

Gambar 2. Tipe dokumen dalam EDI Sumber: (Surjasa, 1998)

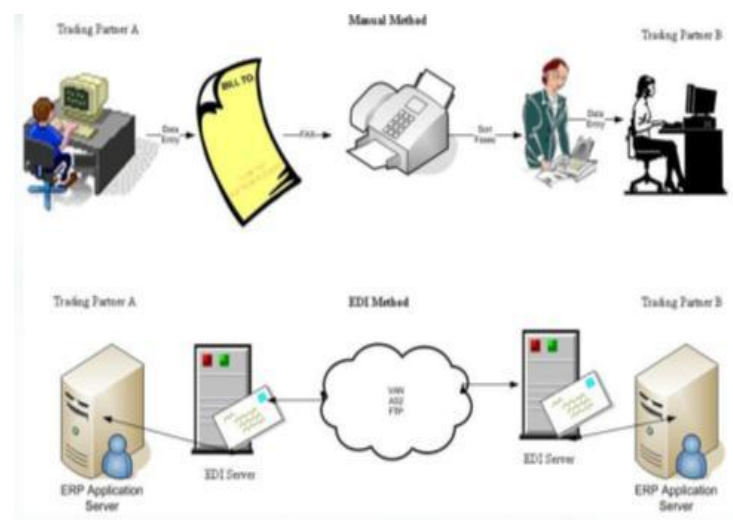

Gambar 3. Perbandingan sistem konvensional dengan EDI

Sumber: (ediacademy, Tanpa Tahun)

\section{METODOLOGI ATAU TEORI}

Metodologi yang digunakan untuk membuat rancang bangun aplikasi transaksi elektronik ritel pupuk dengan metode EDI yaitu dengan menggunakan siklus hidup sistem informasi akuntansi. Dalam bukunya yang berjudul Riset Akuntansi, Husein Umar (1998:20) menjabarkan bahwa siklus hidup sistem informasi akuntansi menyerupai suatu organisme yang berawal dari proses hidup hingga mati. Siklus hidup sistem terdiri dari lima tahapan. Lima tahapan tersebut meliputi tahap perencanaan, tahap analisis, tahap rancangan, 
tahap penerapan dan tahap penggunaan. Dimana dalam setiap tahap tersebut merupakan suatu keberlanjutan dari tahap sebelumnya.

\subsection{Tahap Perencanaan}

Pada tahap perencanaan ini, diidentifikasi masalah yang ada pada objek penelitian (UD. TJM). Permasalahan yang sedang dialami oleh UD. TJM yaitu pada proses cepat tanggap dalam pengelolaan informasi transaksi penjualan pupuk dan pemantauan data barang (stok) di gudang-gudang serta proses komunikasi administrasi antara gudang dan pemilik UD. TJM yang tidak berjalan lancar. Untuk memecahkan permasalahan-permasalahan tersebut, akan dibuat rancang bangun aplikasi transaksi elektronik dengan menggunakan metode electronic data interchange (EDI). Dengan adanya aplikasi EDI, diharapkan dapat membantu pemilik untuk mengontrol keberadaan pupuk agar tidak over stock dan proses pencatatan transaksi penjualan menjadi transparan.

\subsection{Tahap Analisis}

Pada tahapan ini, dimulai dengan pengumpulan data - data mengenai objek penelitian. Pengumpulan data yang dilakukan yaitu dengan cara mengunjungi obyek penelitian, dalam hal ini letak UD. TJM yang terletak di Dusun Krajan RT.13 RW.02 Kecamatan Jenggawah Kabupaten Jember dengan metode wawancara dan observasi langsung.

\subsection{Tahap Rancangan}

Pada tahap rancangan ini, digunakan metode pendekatan sistem berorientasi objek, dengan model perancangan sistem yang digunakan adalah model waterfall yang dapat dilihat pada Gambar 4.

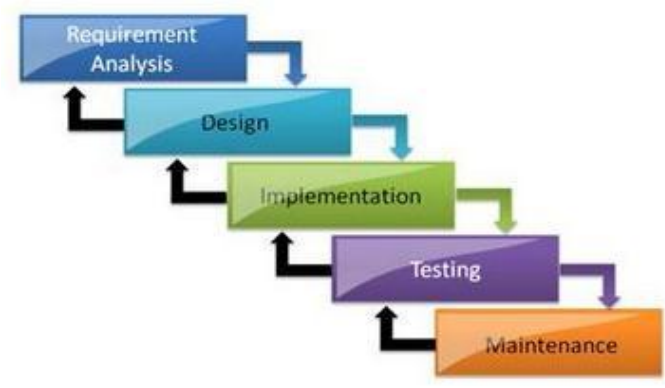

Gambar 4. Model waterfall

Sumber: (Ragompal, 2012)

\subsection{Tahap Penerapan}

Pada tahapan ini yang dilakukan yaitu pengimplementasikan aplikasi pada data yang sudah ada. Sehingga dapat diketahui perbedaan apa yang terjadi saat sebelum menerapkan sistem aplikasi dengan metode EDI dan sesudah penerapan aplikasi tersebut. Dengan demikian, pemilik UD. TJM dapat merasakan perbedaan yang terjadi setelah penggunaan aplikasi tersebut.

\section{HASIL DAN PEMBAHASAN}

Pada bagian ini dipaparkan tentang bagaimana proses perancangan aplikasi elektronik ritel pupuk yang dibangun pada UD. TJM. Aplikasi ini dibangun guna memenuhi kebutuhan sistem yang diinginkan pada UD. TJM, agar proses manajemen transaksi penjualan pupuk, pengontrolan stok barang di gudang dapat terkomputerisasi dan mengurangi kesalahan pencatatan data yang terjadi antara pemilik dan penjaga gudang.

\subsection{Deskripsi umum aplikasi}

Deskripsi umum aplikasi yang dibangun pada penelitian ini adalah aplikasi transaksi elektronik yang dapat saling bertukar informasi meskipun data berada pada aplikasi dan server yang berbeda. Tujuan pembuatan aplikasi ini untuk mengetahui implementasi metode EDI pada transaksi elektronik ritel pupuk di UD. TJM.

\subsection{Analisis kebutuhan}

Aplikasi yang dibangun pada penelitian ini dibagi menjadi 2 aplikasi. Pembuatan dua aplikasi tersebut untuk dapat memberikan gambaran tentang pemanfaatan metode EDI dalam transaksi elektronik. Analisis kebutuhan pada aplikasi pertama, yaitu aplikasi pada bagian pemilik dapat dilihat dari Tabel 1. 
Tabel 1. Analisis kebutuhan aplikasi fredi pemilik

\begin{tabular}{|c|c|}
\hline SRSF ID & Identifikasi \\
\hline SRSFP_01 & $\begin{array}{l}\text { Sistem dapat mengidentifikasi pengguna yang } \\
\text { berhak atau tidak mengakses aplikasi. }\end{array}$ \\
\hline SRSFP_02 & $\begin{array}{l}\text { Sistem dapat memanajemen data produk } \\
\text { (memasukkan data, melihat data, meng-update data, } \\
\text { menghapus data). }\end{array}$ \\
\hline SRSFP_03 & $\begin{array}{l}\text { Sistem dapat memanajemen data gudang } \\
\text { (memasukkan data, melihat data, meng-update data, } \\
\text { menghapus data). }\end{array}$ \\
\hline SRSFP_04 & $\begin{array}{l}\text { Sistem dapat memanajemen data distribusi pupuk } \\
\text { ke gudang-gudang. (memasukkan data dan melihat } \\
\text { data). }\end{array}$ \\
\hline SRSFP_05 & $\begin{array}{l}\text { Sistem dapat memanajemen data transaksi } \\
\text { pembelian pupuk (memasukkan data dan melihat } \\
\text { data). }\end{array}$ \\
\hline SRSFP_06 & $\begin{array}{l}\text { Sistem dapat memanajemen data transaksi } \\
\text { penjualan pupuk (memasukkan data dan melihat } \\
\text { data). }\end{array}$ \\
\hline SRSFP_07 & $\begin{array}{l}\text { Sistem dapat memanajemen data laporan, berupa } \\
\text { laporan pembelian, laporan penjualan dan laporan } \\
\text { persediaan (melihat data dan mencetak data). }\end{array}$ \\
\hline SRSFP_08 & $\begin{array}{l}\text { Sistem dapat mengakses data agen yang telah } \\
\text { dimasukkan pengguna pada aplikasi bagian gudang } \\
\text { (melihat data). }\end{array}$ \\
\hline SRSFP_09 & $\begin{array}{l}\text { Sistem dapat mengakses data penjualan yang telah } \\
\text { dimasukkan pengguna pada aplikasi bagian gudang } \\
\text { (melihat data). }\end{array}$ \\
\hline SRSFP_10 & $\begin{array}{l}\text { Sistem dapat memberikan persetujuan (approve) } \\
\text { pada masukan data penjualan di bagian gudang } \\
\text { dengan mengeluarkan bukti tagihan (invoice). }\end{array}$ \\
\hline
\end{tabular}

Sedangkan analisis kebutuhan aplikasi kedua, yaitu aplikasi pada bagian gudang dapat dilihat pada Tabel 2.

Tabel 2. Analisis kebutuhan aplikasi fredi gudang

\begin{tabular}{|c|l|}
\hline SRSF ID & \multicolumn{1}{|c|}{ Identifikasi } \\
\hline SRSFG_01 & $\begin{array}{l}\text { Sistem dapat mengidentifikasi pengguna yang } \\
\text { berhak atau tidak mengakses aplikasi. }\end{array}$ \\
\hline SRSFG_02 & $\begin{array}{l}\text { Sistem dapat memanajemen data agen } \\
\text { (memasukkan data, melihat data, meng-update } \\
\text { data, menghapus data). }\end{array}$ \\
\hline SRSFG_03 & $\begin{array}{l}\text { Sistem dapat mengakses data produk yang telah } \\
\text { dimasukkan pengguna pada aplikasi bagian } \\
\text { pemilik (melihat data). }\end{array}$ \\
\hline SRSFG_04 & $\begin{array}{l}\text { Sistem dapat mengakses data distribusi pupuk } \\
\text { yang dimasukkan pada aplikasi bagian pemilik } \\
\text { ke gudang tujuan (melihat data). }\end{array}$ \\
\hline SRSFG_05 & $\begin{array}{l}\text { Sistem dapat memanajemen data transaksi } \\
\text { penjualan pupuk (memasukkan data dan melihat } \\
\text { data). }\end{array}$ \\
\hline SRSFG_06 & $\begin{array}{l}\text { Sistem dapat menerima pesan persetujuan } \\
\text { tentang penjualan yang diberikan aplikasi bagian } \\
\text { pemilik ke gudang (menerima bukti tagihan dan } \\
\text { mencetak bukti tagihan) }\end{array}$ \\
\hline
\end{tabular}

Untuk kebutuhan non-fungsional sistem aplikasi yang akan dibangun, dapat dilihat pada Tabel 3.

Tabel 3. Analisis kebutuhan non-fungsional aplikasi fredi pemilik dan aplikasi fredi gudang

\begin{tabular}{|c|c|c|}
\hline SRSNF ID & Parameter & Kebutuhan \\
\hline SRSNF_01 & $\begin{array}{l}\text { Penggunaan } \\
\text { sumber daya }\end{array}$ & $\begin{array}{l}\text { Sistem harus dapat digunakan } \\
\text { oleh beberapa komputer secara } \\
\text { bersamaan yang tergabung ke } \\
\text { dalam suatu jaringan } \\
\text { komunikasi, karena nantinya } \\
\text { sistem akan digunakan di } \\
\text { beberapa komputer yang ada di } \\
\text { beberapa gudang yang berbeda } \\
\text { lokasi. }\end{array}$ \\
\hline SRSNF_02 & Tampilan & $\begin{array}{l}\text { Sistem harus mempunyai } \\
\text { tampilan yang menarik dan } \\
\text { mudah digunakan oleh } \\
\text { penggunanya ( } \text { ser friendly) } \\
\text { untuk memudahkan pengguna } \\
\text { untuk memahami sistem yang } \\
\text { digunakan. }\end{array}$ \\
\hline SRSNF_03 & Fleksibilitas & $\begin{array}{l}\text { Sistem harus dapat digunakan } \\
\text { pada berbagai jenis sistem } \\
\text { operasi seperti windows, linux, } \\
\text { mac, dan lain-lain karena itu } \\
\text { digunakan bahasa pemrograman } \\
\text { yang berbasis website supaya } \\
\text { lebih mudah digunakan di } \\
\text { berbagai sistem operasi yang } \\
\text { berbeda. }\end{array}$ \\
\hline SRSNF_04 & Respon & $\begin{array}{l}\text { Sistem harus mempunyai respon } \\
\text { tepat waktu (real-time) dalam } \\
\text { penyampaian informasinya, } \\
\text { sehingga dapat memberikan } \\
\text { informasi yang up-to-date. }\end{array}$ \\
\hline SRSNF_05 & Ketersediaan & $\begin{array}{l}\text { Sistem harus dapat diakses dari } \\
\text { mana saja dan kapan saja selama } \\
24 \text { jam. }\end{array}$ \\
\hline SRSNF_06 & Keamanan & $\begin{array}{l}\text { Sistem harus mempunyai } \\
\text { keamanan sistem untuk } \\
\text { mengaksesnya, sehingga sistem } \\
\text { tidak sembarangan digunakan } \\
\text { oleh pihak-pihak yang tidak } \\
\text { bertanggung jawab. }\end{array}$ \\
\hline
\end{tabular}

\subsection{Desain sistem}

Desain sistem untuk rancang bangun aplikasi transaksi elektronik ritel dengan metode EDI akan digambarkan dengan bisnis proses (business process/BP), diagram alur kerja (workflow diagram), usecase diagram, skenario, activity diagram, sequence diagram, class diagram dan entity relation diagram (ERD). Bisnis proses pada penelitian ini dapat dilihat pada Gambar 5. 


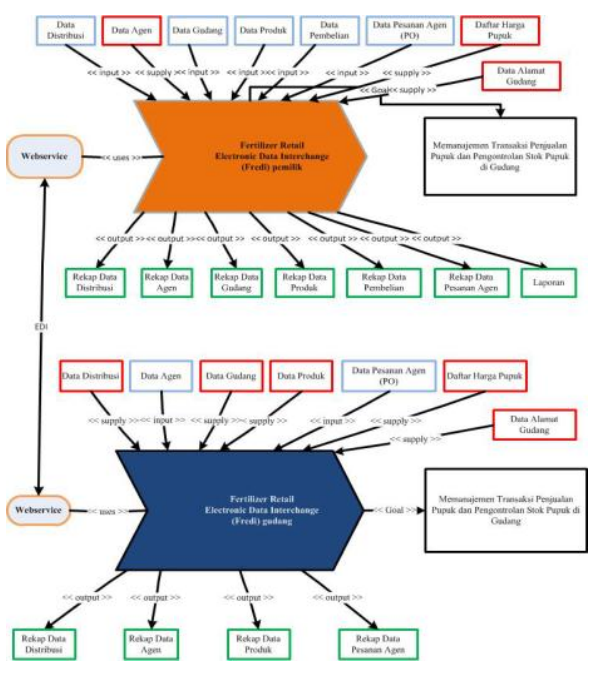

Gambar 5. Bisnis Proses

Usecase dalam proses pembuatan rancang bangun aplikasi transaksi elektronik ritel dengan metode EDI dapat dilihat pada Gambar 6 dan Gambar 7.

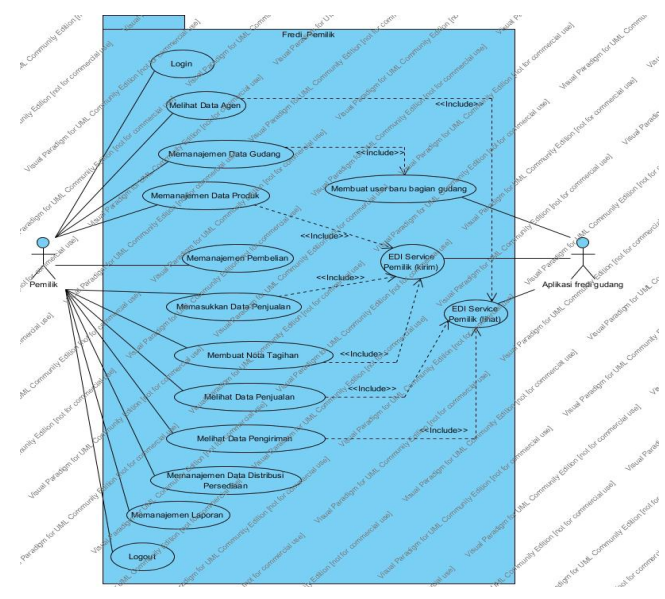

Gambar 6. Usecase aplikasi fredi pemilik

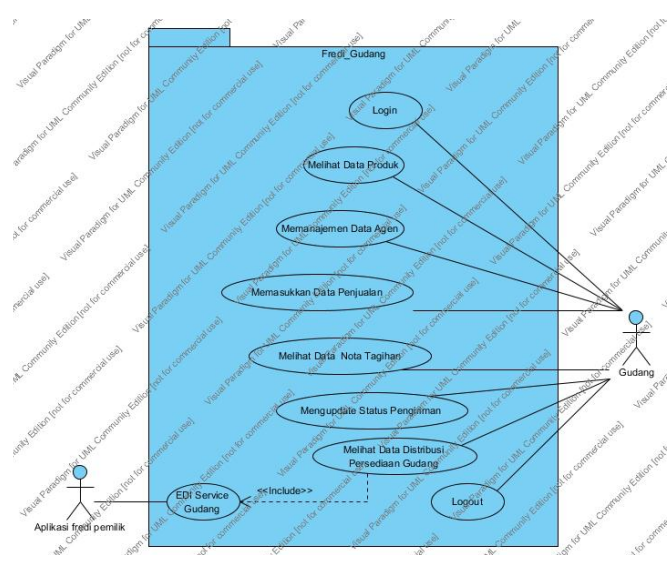

Gambar 7. Usecase aplikasi fredi pemilik
Class diagram pada aplikasi fredi bagian pemilik dapat dilihat pada Gambar 8. Sedangkan class diagram aplikasi fredi bagian gudang dapat dilihat pada Gambar 9.

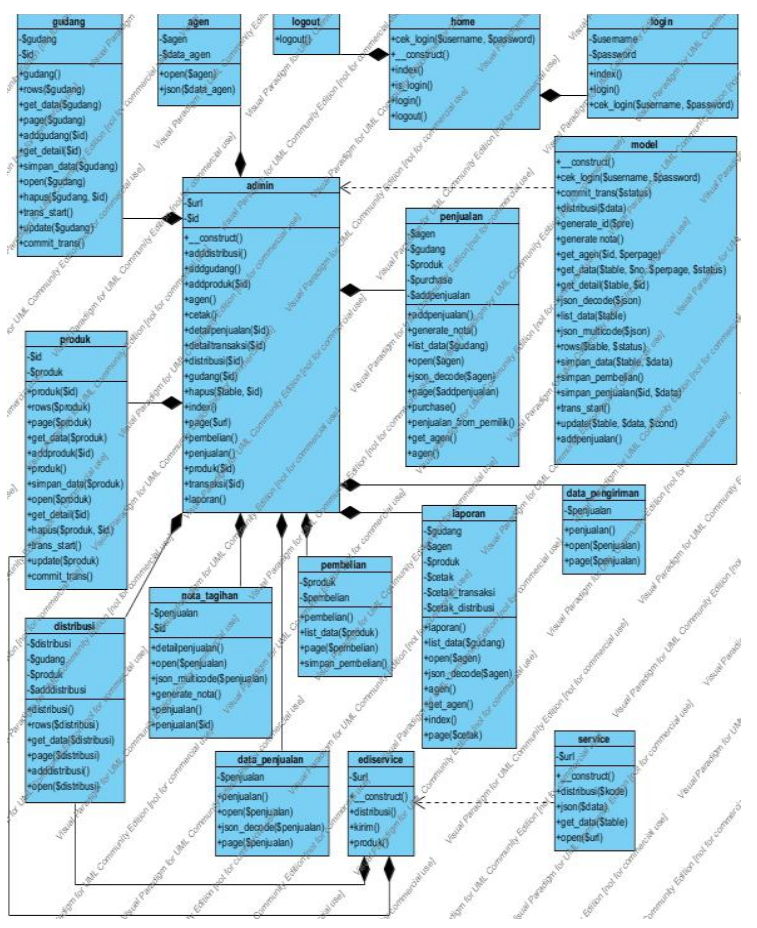

Gambar 8. Class diagram aplikasi fredi pemilik

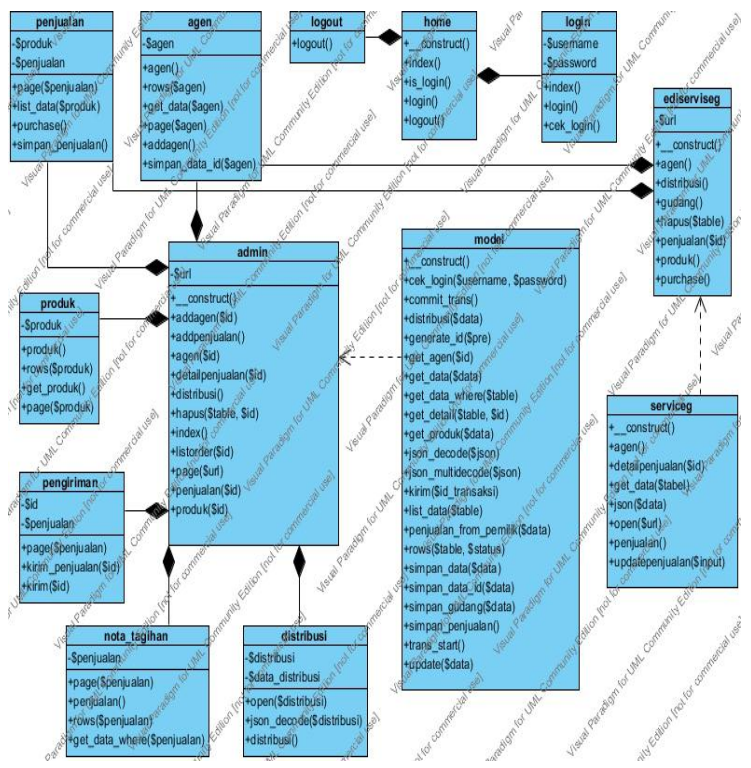

Gambar 9. Class diagram aplikasi fredi gudang

ERD pada aplikasi fredi bagian pemilik dapat dilihat pada Gambar 10. Sedangkan ERD aplikasi fredi bagian gudang dapat dilihat pada Gambar 11. 


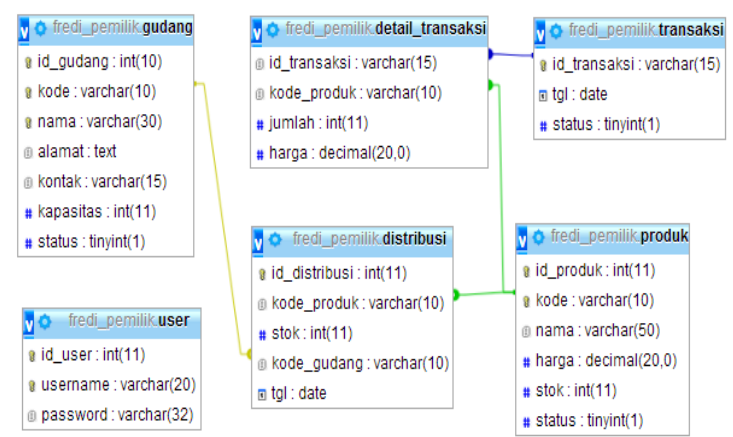

Gambar 10. ERD aplikasi fredi pemilik

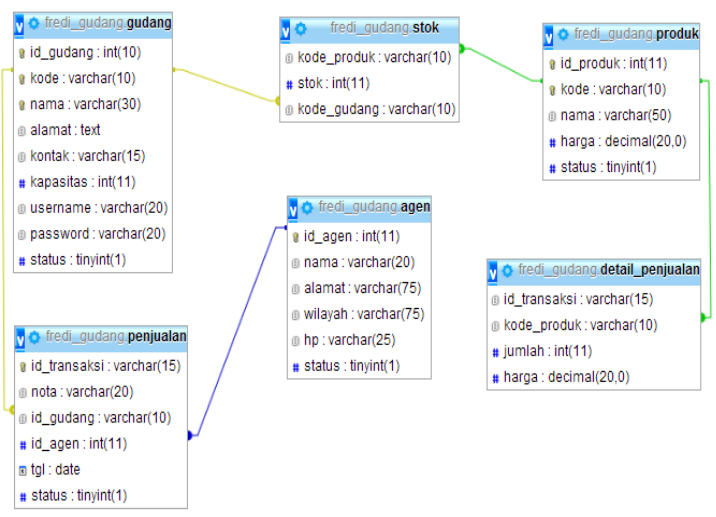

Gambar 11. ERD aplikasi fredi gudang

\subsection{Implementasi hasil dan pembahasan}

Pada tahap ini, desain perancangan yang telah dibuat akan diimplementasikan ke dalam bahasa pemrograman PHP berbasis OOP. Proses pengimplementasian metode EDI pada aplikasi fredi pemilik dan aplikasi fredi gudang dapat dilihat pada Gambar 12 sampai Gambar.

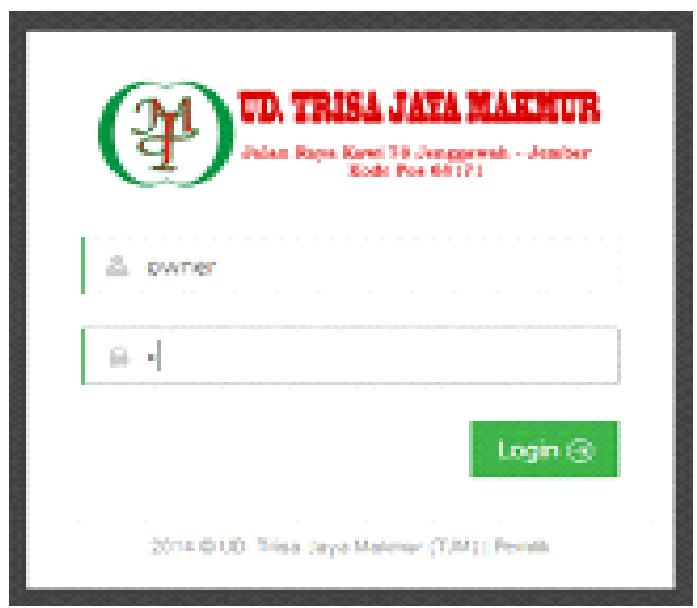

Gambar 12. Halaman login aplikasi fredi pemilik
Ketika username dan password yang dimasukkan pengguna benar, dalam artian data yang dimasukkan sama dengan data di dalam database, maka pengguna berhasil masuk ke aplikasi dan masuk ke halaman dashboard seperti Gambar 13.

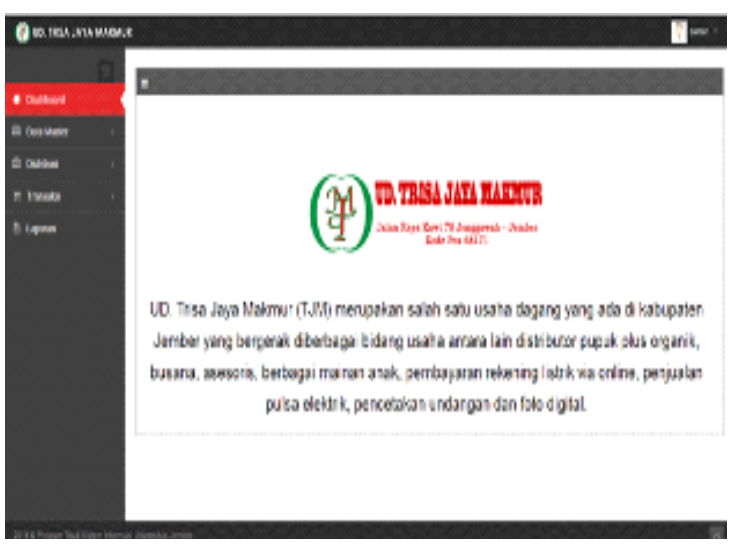

Gambar 13. Halaman awal admin aplikasi fredi pemilik (menu dashboard)

Setelah berhasil masuk ke dalam aplikasi, pengguna dapat mengakses menu-menu yang ada pada aplikasi tersebut. Jika pengguna ingin mengakses submenu data agen, pengguna dapat memilih submenu data agen seperti yang nampak pada Gambar 14. Pada submenu data agen, penggunaan metode EDI yaitu data agen yang dimasukkan oleh pengguna aplikasi fredi gudang dapat diakses oleh pengguna aplikasi fredi pemilik. Sehingga terjadi proses tukar menukar data antar kedua aplikasi tersebut. Submenu data agen pada aplikasi fredi gudang dapat dilihat pada Gambar 15.

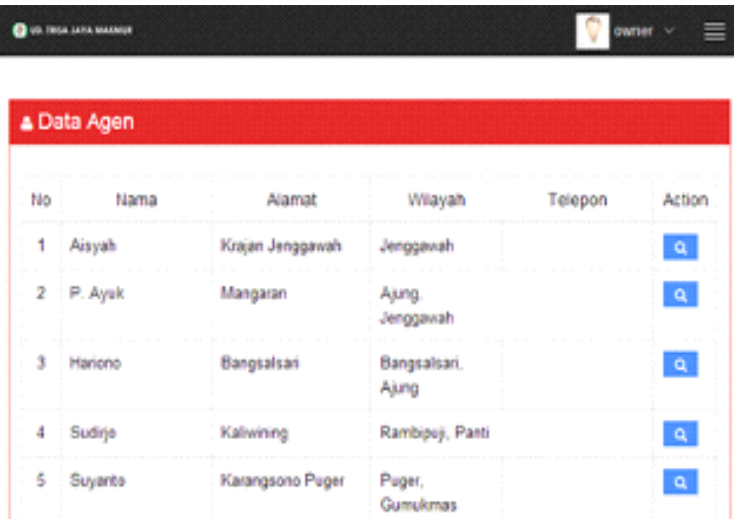

Gambar 14. Halaman data agen aplikasi fredi pemilik 


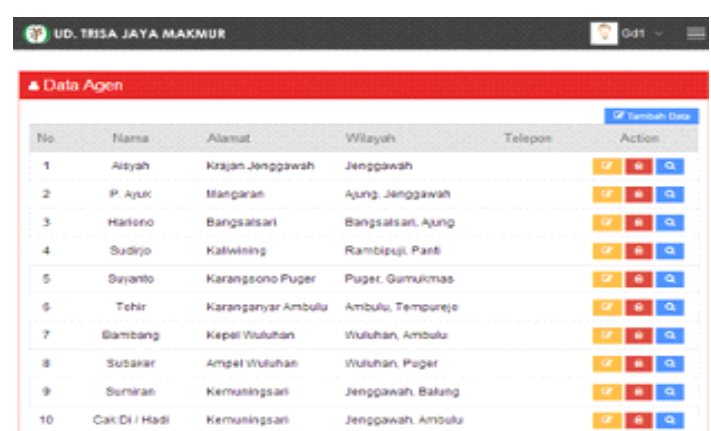

Gambar 15. Halaman data agen aplikasi fredi gudang

Di dalam submenu data agen, terdapat tombol, yang berfungsi untuk melihat rekap transaksi penjualan yang pernah dilakukan agen tersebut. Detail transaksi penjualan yang pernah dilakukan agen tersebut, dapat dilihat pada Gambar 16.

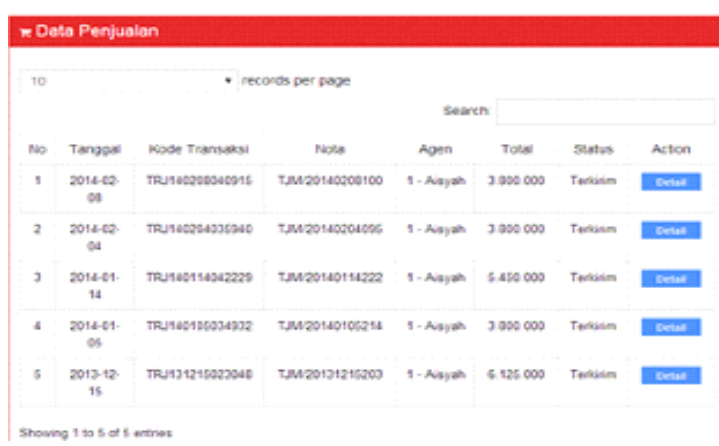

Gambar 16. Rekap transaksi penjualan yang pernah dilakukan agen

Untuk melihat detail transaksi penjualan yang pernah dilakukan agen, dapat kita lihat dengan cara menekan tombol detail pada tampilan Gambar 16 sehingga akan muncul detail transaksi penjualannya seperti Gambar 17.

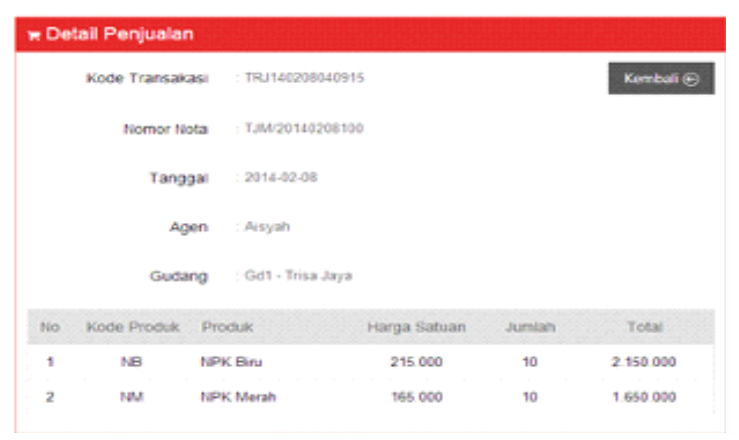

Gambar 17. Detail transaksi penjualan yang dilakukan agen
Pada aplikasi fredi pemilik, pengguna juga dapat memanajemen data produk. Proses yang dapat dilakukan pada submenu data produk ini yaitu melihat seluruh data produk, menambah data produk, mengedit data produk, dan menghapus data produk. Untuk melihat seluruh data produk, pengguna dapat memilih submenu data produk maka akan muncul tampilan seperti pada Gambar 18.

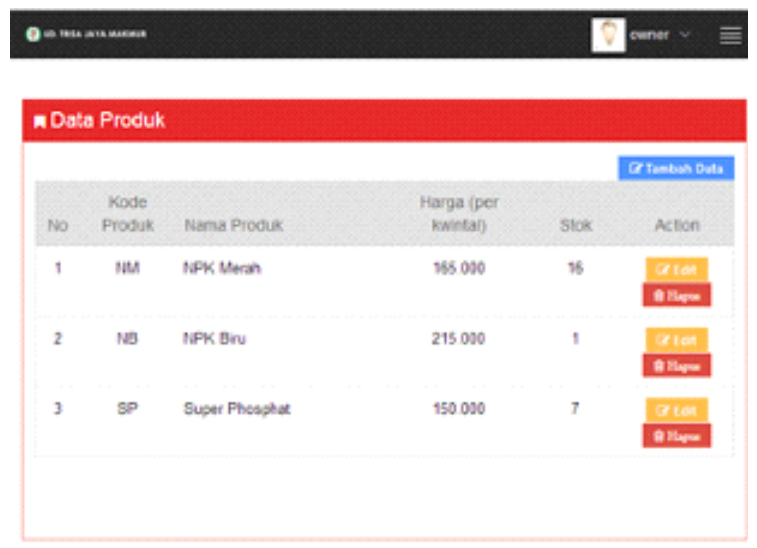

Gambar 18. Halaman data produk aplikasi fredi pemilik

Kemudian untuk memasukkan data produk baru yang ingin dimasukkan ke dalam sistem, pengguna dapat menekan tombol "tambah data" sehingga akan muncul tampilan seperti pada Gambar 19.

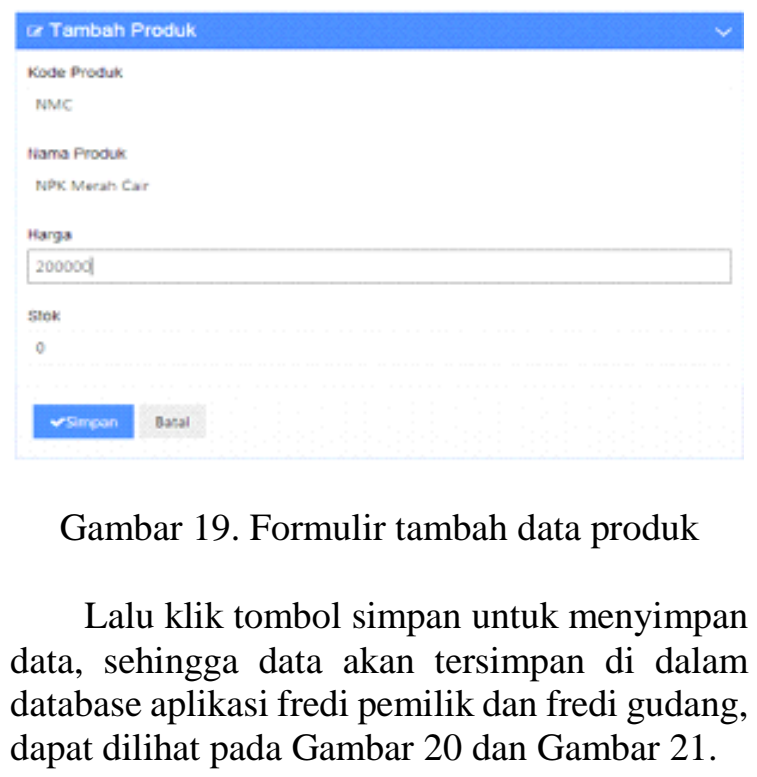




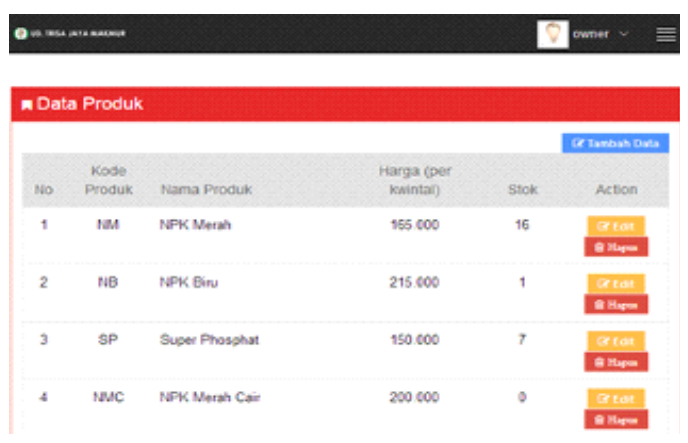

Gambar 20. Data produk berhasil ditambah pada aplikasi fredi pemilik

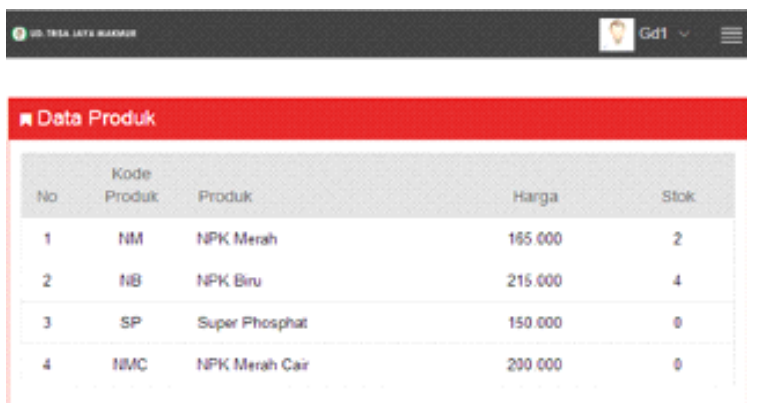

Gambar 21. Data produk berhasil ditambah pada aplikasi fredi gudang

Selain submenu data agen dan data produk, aplikasi fredi pemilik juga mempunyai submenu data gudang. Ketiga submenu tersebut merupakan bagian dari menu utama data master. Tampilan submenu data gudang, dapat dilihat pada Gambar 22.

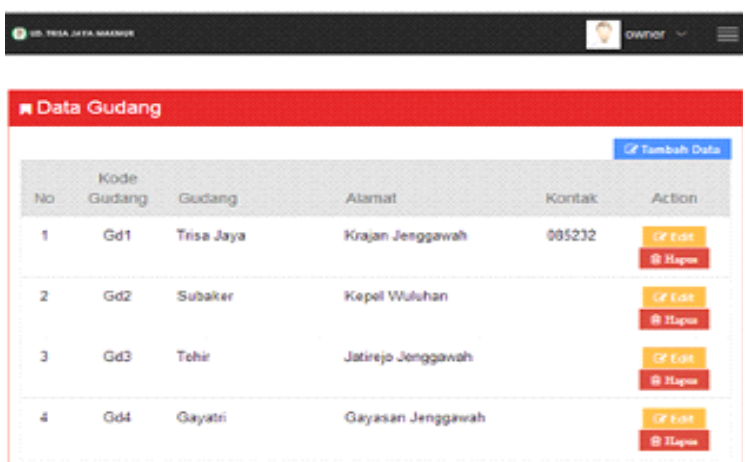

Gambar 22. Halaman data gudang aplikasi fredi pemilik

Untuk memasukkan data gudang baru yang ingin dimasukkan ke dalam sistem, pengguna dapat menekan tombol "tambah data" sehingga akan muncul tampilan seperti pada Gambar 23.

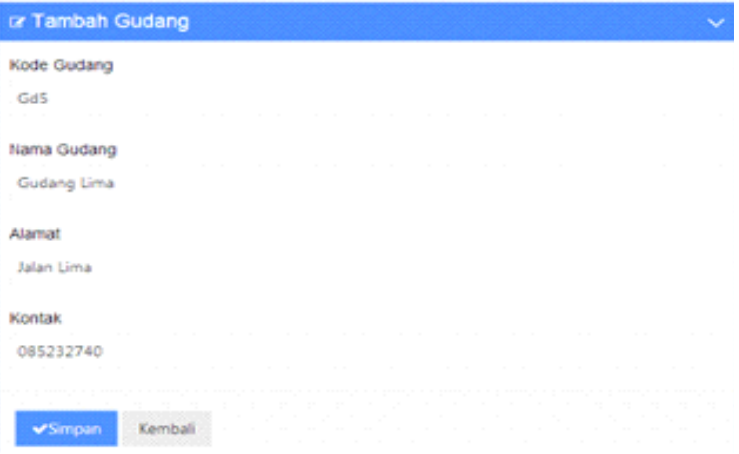

Gambar 23. Formulir tambah gudang

Lalu klik tombol simpan untuk menyimpan data, sehingga data akan tersimpan di dalam database dan akan muncul seperti Gambar 24.

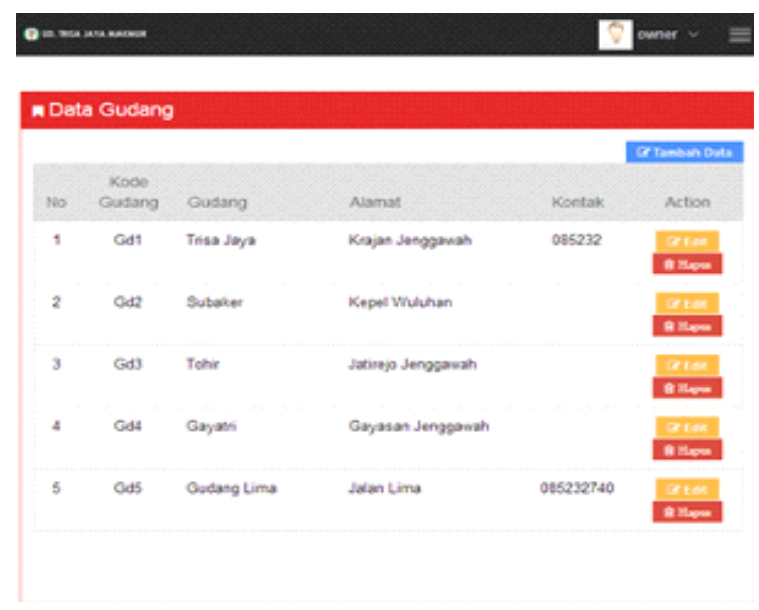

Gambar 24. Data gudang bertambah

Penambahan data gudang yang dilakukan pengguna pada aplikasi fredi pemilik, akan berdampak pada pengguna aplikasi fredi gudang. Sehingga secara otomatis, penambahan gudang juga akan menambah pengguna pada aplikasi fredi gudang, dapat dilihat pada Gambar 25.
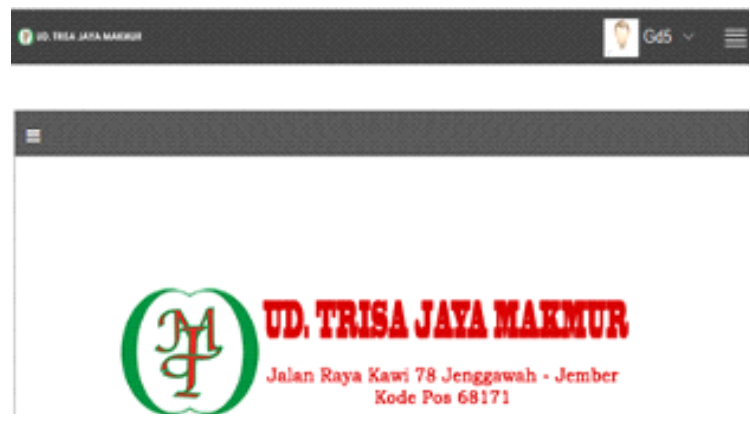

Gambar 25. Pengguna baru aplikasi fredi gudang 


\section{KESIMPULAN}

Kesimpulan yang dapat diambil dari hasil penelitian yang sudah dilakukan dengan mengimplementasikan metode EDI pada aplikasi fredi pemilik dan fredi gudang adalah kedua aplikasi tersebut dapat saling bertukar informasi data apa saja yang menjadi masukan dari aplikasi utama sehingga dapat diakses dan digunakan pada aplikasi lainnya. Selain itu, pengimplementasian aplikasi transaksi elektronik dengan metode EDI pada kedua aplikasi tersebut dapat meminimalisir kesalahan dalam memasukkan data. Sehingga data transaksi yang dimasukkan lebih transparan dan dapat diketahui bersama. Dan juga dengan menggimplementasikan metode EDI dapat mengurangi waktu dan tenaga pemilik untuk dapat mengetahui informasi transaksi apa saja yang terjadi di bagian gudang. Sehingga proses pengontrollan barang dan stok gudang dapat selalu diawasi oleh pemilik.

\section{DAFTAR PUSTAKA}

[1] Bodnar, George H., and William S. Hopwood. Sistem Informasi Akuntansi Edisi 9. Yogyakarta: ANDI, 2007.

[2] Devina, Ria Apriyani. "Analisis Dan Rancang Bangun Sistem Informasi Pengolahan Data Pembayaran Kredit Rumah Berjangka Pada PT. Pulau Jaya Abadi Palembang Menggunakan Pemrograman Delphi 2007 Dan Sql Server 2008." Jurnal Mahasiswa Sistem Informasi STMIK PalComTech, 2013: 2.

[3] ediacademy.n.d.http://ediacademy.com/Wh yAttendEDITraining.html (accessed April 21, 2014).

[4] Gunawan, Andri Wisnu. Peningkatan Performa Sistem Logistik Perusahaan Retail dengan Menggunakan Electronic Data Interchange (EDI). Skripsi, Jakarta: Fakultas Teknik Program Studi Teknik Industri Universitas Indonesia, 1999.

[5] Liegl, Philipp. Electronic Data Interchange 188.422 E-Commerce Technologien. Paper Presentation, Austria: Institute of Software Technology and Interactive Systems Vienna University of Technology, 2009.

[6] Ramgopal, Arte \&. 2012. http://www.presentation-

process.com/waterfall-diagram-in- powerpoint.html (accessed November 29, 2013).

[7] Surjasa, Dadang. Membangun Model Konseptual Electronic Data Interchange (EDI) dan Barcode pada Saluran Distribusi. Tesis, Jakarta: Program Pascasarjana Program Studi Teknik Mesin Peminatan Manajemen Industri Fakultas Teknik Universitas Indonesia, 1998.

[8] Umar, Husein. Riset Akuntansi. Jakarta: PT. Gramedia Pustaka Utama, 1998.

\section{Biodata Penulis}

Nelly Oktavia Adiwijaya, lahir di Sumenep tanggal 24 Oktober. Pendidikan S1 di Jurusan MIPA-Matematika Universitas Jember, Pendidikan S2 di Jurusan Teknik Elektro Institut Teknologi Bandung dengan Program Studi Game Teknologi. 